\title{
Six-Minute Walk Test as a Guide for Walking Prescription for Patients with Chronic Obstructive Pulmonary Diseases
}

\author{
Baskaran Chandrasekaran, Kalyan Chakravarthy Reddy ${ }^{1}$ \\ Center for Exercise, Sports Science, Medicine and Research, Manipal Academy of Higher Education, 'Department of Physiotherapy, SOAHS, Manipal Academy of \\ Higher Education, Manipal, Karnataka, India
}

\section{Abstract}

Exercise training in chronic respiratory disorders such as chronic obstructive pulmonary disease (COPD) is an essential component of pulmonary rehabilitation, but physical activity for maintenance of benefits in COPD after outpatient/inpatient rehabilitation is a neglected one. The dosage of walking is not "prescribed" properly by health-care providers for maintenance of muscle mass and improving quality of life. If the ground or treadmill walking is appropriately dosed and prescribed based on 6-min walk test (6MWT), the unsupervised ground walking may be a useful alternative to supervised aerobic fitness programs for achieving fitness benefits. This article provides an overview of dosing and measuring the walking program (either ground or treadmill) objectively to novice therapists and primary care physicians based on the 6MWT to COPD patients.

Keywords: Benefits, ground walk, prescription, six-minute walk distance, six-minute walk test, treadmill walk

\section{INTRODUCTION}

Exercise intolerance and poor quality of life are commonly addressed issues in chronic obstructive pulmonary disease (COPD) ${ }^{[1]}$ Exercise-based pulmonary rehabilitation improves exercise tolerance and functional capacity, thereby improving occupational work tolerance and quality of life in COPD individuals. ${ }^{[2]}$ Walking is commonly prescribed in primary care to enhance exercise tolerance and maintenance of quality of life in COPD individuals with moderate-to-severe GOLD criteria. ${ }^{[1]}$ However, the compliance is poor. ${ }^{[3]}$ Adequately dosed walking improves functional capacity and quality of life in COPD patients.

The walk training is suggested in an unstructured (nearly placebo) and nonsystematic manner such as "every day at least $30 \mathrm{~min}$ " in people with chronic respiratory disorders. ${ }^{[4]}$ There is a chance of overdosing or underdosing the walk training at the primary care or public health-care level if walking is prescribed nonsystematically. The method of target heart rate is impractical or not feasible at the public health level or fundamental clinical level or for a home prescription. ${ }^{[5]}$

Six-minute walk test (6MWT) is a simple, reliable test used for the measurement of functional capacity in a variety of chronic lung disorders. ${ }^{[6]}$ For quantification of intervention effects and

\begin{tabular}{|l|l|}
\hline \multicolumn{2}{|c|}{ Access this article online } \\
\hline Quick Response Code: & Website: \\
\hline & www.ijrconline.org \\
\hline & \\
\hline
\end{tabular}

disease progression, $6 \mathrm{MWT}$ is proven to be a handy measure justified by the overwhelming current literature ${ }^{[7]}$ However, its usefulness in the prescription of walking (aerobic activity) is little known. The aim of the present review is to provide clinicians/therapists with basic understanding of 6-min walk distance (6MWD) calculation and exercise prescription based on it. Further, it may provide a comprehensive knowledge on basic and advanced outcome measures of 6MWT.

\section{Six-minute walk test}

6MWT is a self-paced submaximal field exercise test employed for determining the functional capacity, disease intensity, and disease progression of the patients with COPD. ${ }^{[7]}$ The variability of 6MWT depends on the anthropometric traits, physical activity of the individual, racial, cross-cultural differences, motivation, altitude, humidity, clothing, and timing of the test. ${ }^{[8]}$ Its standardization has been elaborately discussed in the previous literature for ensuring the validity and reliability of $6 \mathrm{MWT} \cdot{ }^{[8,9]}$ The outcome measures monitored

Address for correspondence: Mr. Baskaran Chandrasekaran, Center for Exercise, Sports Science, Medicine and Research, Manipal Academy of Higher Education, Manipal, Karnataka, India. E-mail: baskaran.c@manipal.edu

This is an open access journal, and articles are distributed under the terms of the Creative Commons Attribution-NonCommercial-ShareAlike 4.0 License, which allows others to remix, tweak, and build upon the work non-commercially, as long as appropriate credit is given and the new creations are licensed under the identical terms.

For reprints contact: reprints@medknow.com

How to cite this article: Chandrasekaran B, Reddy KC. Six-Minute walk test as a guide for walking prescription for patients with chronic obstructive pulmonary diseases. Indian J Respir Care 2018;7:73-6. 
by the $6 \mathrm{MWT}$ are actual $6 \mathrm{MWD}$, predicted or ideal $6 \mathrm{MWD}$ percentage from normative data, and 6MWD percentage. ${ }^{[10]}$ Vitals (pressure changes, desaturation, and heart rate variation) and distance-weight product $(6 \mathrm{MWD} \times \mathrm{BW})$ are also useful outcomes in $6 \mathrm{MWT}^{[11]}$ The primary outcome measure that is used widely in the available literature for calculating walk intensity is the distance walked (6MWD). ${ }^{[9,11]}$

\section{Procedure and instructions of six-minute walk test}

6MWT is standardized well by the American Thoracic Society (ATS) and the American Association for Respiratory Care ${ }^{[9]} 6 \mathrm{MWT}$ is administered in the $30 \mathrm{~m}$ hallway with cones at the end. The patients are instructed to cover the maximal distance in $6 \mathrm{~min}$ (not as fast as possible). The encouragement during 6MWT is also standardized because the former is found to be influencing the walk distance of the patient. ${ }^{[12]}$ The environment should be calm and accessible to resuscitation. 6MWT should be administered individually not as a group because the competition may increase the walk distance falsely.

\section{Calculation of walk intensity and progression from actual six-minute walk distance}

Recently, exercise prescription based on 6MWD has acquired a significant interest in chronic respiratory disorders. ${ }^{[13,14]}$ The existing evidence, however, is complicated by deriving maximal oxygen consumption from the predicted equations which is proved to be less reliable and requires expertise. ${ }^{[15]}$ The following method of target walking distance or speed calculation is much more straightforward and requires less skill.

Usually, $80 \%-90 \%$ of the speed in actual $6 \mathrm{MWT}$ is assigned an initial speed of walk training either in ground or treadmill. ${ }^{[13]}$ The ideal duration is $15-20 \mathrm{~min}$ of walk. If the patients are very debilitated, the walk period can be split up into healthy levels of walk duration (5-5-5 or 6-6-8 min termed interval training). The walk training may be carried at the pace of $80 \%$ of actual 6MWT speed at the $1^{\text {st }}$ week of walking, $90 \%$ of 6 MWT speed during the $2^{\text {nd }}$ week, and $100 \%$ of 6 MWT speed while following the $3^{\text {rd }}$ week. Then, the actual 6MWD is reassessed (appraised), and the walk training shall be based on $80 \%-100 \%$ of new $6 \mathrm{MWT}$ speed. Thus, walk training should be progressed by the swiftness of the appraised 6MWT every 3 weeks. The speed is to be maintained at a minimum duration of 15 min excluding warm-up and cool down walk at a slower pace.

actual 6MWT speed $=\frac{\text { actual } 6 \mathrm{MWD}}{100} \mathrm{~km} / \mathrm{h}$

walk training speed $=\frac{\text { actual } 6 \mathrm{MWD}}{100} \mathrm{~km} / \mathrm{h}$

walk training speed at $1^{\text {st }}$ week $=\frac{80}{100} \times$ actual 6 MWD speed

walk training speed at $2^{\text {st }}$ week $=\frac{90}{100} \times$ actual $6 \mathrm{MWD}$ speed

walk training speed at $3^{\text {rd }}$ week $=$ actual $6 \mathrm{MWD}$ speed
Once the walk training speed is completed at the pace of actual 6-min walk speed for $20 \mathrm{~min}$, the newer 6MWD may be measured, and walk training speed can be calculated by it for the following 3 weeks. For treadmill walk training, this walking speed above and duration parameters can be applied efficiently. Remember, the inclination is to be set at $0^{\circ}$ for using the above formula. If inclination in a treadmill is present, then the above calculation will underestimate the patient's walking capacity.

\section{Ground walk training prescription}

Ground walking is preferred by patients and physicians because it is functional, simple, inexpensive, and readily applicable. ${ }^{[16]}$ To make ground walking to be useful for reaping the health benefits, the application of exercise training principles (frequency, intensity, and duration) in ground walk training also is a must. The walk speed or intensity of ground walk training is calculated as follows:

Maximum distance that may be walked in $20 \mathrm{~min}$ $($ meters $)(20 \mathrm{MWD})=$ actual $6 \mathrm{MWD} \times 3.33 \mathrm{~m}$

Initial training distance to be walked in $20 \mathrm{~min}$ at $1^{\text {st }}$ week $=$

$$
\frac{80}{100} \times 20 \text { MWD m }
$$

Followup training distance to be walked in $20 \mathrm{~min}$ at

$$
2^{\text {nd }} \text { week }=\frac{90}{100} \times 20 \mathrm{MWD} \mathrm{m}
$$

Final training distance to be walked in $20 \mathrm{~min}$ at $3^{\text {rd }}$ week $=20 \mathrm{MWD} \mathrm{m}$

After 3 weeks of field walk training, new 6MWT is to be employed and new 6MWD to be sought out. From there, new 20MWD may be calculated, and walk training for next 3 weeks at $80 \%, 90 \%$, and $100 \%$ of new $20 \mathrm{MWD}$ may be administered for progression. The ground walking is to be managed for at least 5 days a week interspersed with minimal strengthening exercises for large strap muscles (quadriceps and latissimus) for attaining maximal benefit out of the training.

The simulated cases are presented below for better understanding:

\section{Case 1}

A retired teacher, a known case of stable COPD (not exacerbated for at least 4 months of physicians' visit) was referred for rehabilitation. Initial 6MWT revealed a $6 \mathrm{MWD}$ of $360 \mathrm{~m}(67 \%$ predicted maximal distance). He lives at a place inaccessible to pulmonary rehabilitation. He has a personal motorized treadmill. Chart a treadmill walking program based on the $6 \mathrm{MWT}$. The devising of walk program will be as follows:

Actual 6MWD patient walked $=360 \mathrm{~m}$

Actual 6MWT speed $($ maximum speed $)=($ actual $6 \mathrm{MWD}) / 100 \mathrm{~km} / \mathrm{h}=360 / 100=3.6 \mathrm{~km} / \mathrm{h}$

Treadmill walk training speed at $1^{\text {st }}$ week $=80 / 100 \times$ actual $6 \mathrm{MWD}$ speed $=80 / 100 \times 3.6=2.9 \mathrm{~km} / \mathrm{h}$ for $15-20 \mathrm{~min}$. 
The warm-up and cool down speed maybe $2.5 \mathrm{~km} / \mathrm{h}$ for $2 \mathrm{~min}$ each for $1^{\text {st }}$-week walk training.

Treadmill walk training speed at $2^{\text {nd }}$ week $=90 / 100 \times$ actual $6 \mathrm{MWD}$ speed $=90 / 100 \times 3.6=3.3 \mathrm{~km} / \mathrm{h}$ for $15-20 \mathrm{~min}$.

The warm-up and cool down rate maybe $2.5 \mathrm{~km} / \mathrm{h}$ for $2 \mathrm{~min}$ each for $2^{\text {nd }}$-week walk training.

Treadmill walk training speed at $3^{\text {rd }}$ week $=$ actual $6 \mathrm{MWD}$ speed $=3.6 \mathrm{~km} / \mathrm{h}$ for $15-20 \mathrm{~min}$.

The warm-up and cool down rate maybe $3 \mathrm{~km} / \mathrm{h}$ for $2 \mathrm{~min}$ each for $3^{\text {rd }}$-week walk training.

\section{Progression}

A new 6MWT may be employed at the end of the $3^{\text {rd }}$ week of the walk training. The resultant $6 \mathrm{MWD}$ may be used to plot new walk training regimen as $80 \%, 90 \%$, and $100 \%$ of resultant new $6 \mathrm{MWD}$ for the next $1^{\text {st }}, 2^{\text {nd }}$, and $3^{\text {rd }}$ week, respectively, for $20 \mathrm{~min}$.

\section{Case 2}

A rickshaw puller known case of stable COPD (not exacerbated for at least 4 months of physicians' visit) was referred for rehabilitation. He could not afford to get a treadmill or join outpatient pulmonary rehabilitation. Initial 6MWT revealed a 6MWD of $360 \mathrm{~m}$ (67\% predicted maximal distance). Chart, a ground walking program, based on the 6MWT. The devising of walk program will be as follows:

Actual 6MWD patient walked $=360 \mathrm{~m}$

Maximal distance that may be ground walked in $20 \mathrm{~min}$ (meters) $(20 \mathrm{MWD})=$ actual $6 \mathrm{MWD} \times 3.33 \mathrm{~m}$ $=360 \times 3.33 \mathrm{~m}=1200 \mathrm{~m}$

Initial ground distance to be walked in $20 \mathrm{~min}$ at $1^{\text {st }}$ week $=80 / 100 \times 20 \mathrm{MWD} \mathrm{m}=80 / 100 \times 1200=960 \mathrm{~m}$ in $20 \mathrm{~min} \approx 1 \mathrm{~km}$ in $20 \mathrm{~min}$

Followup training distance to be walked in $20 \mathrm{~min}$ at $2^{\text {nd }}$ week $=90 / 100 \times 20 M W D \mathrm{~m}=90 / 100 \times 1200=1080 \mathrm{~m}$ in $20 \mathrm{~min} \approx 1.1 \mathrm{~km}$ in $20 \mathrm{~min}$

Final training distance to be walked in $20 \mathrm{~min}$ at $3^{\text {rd }}$ week $=20$ MWD meters $=1200 \mathrm{~m}$ in $20 \mathrm{~min} \approx 1.2 \mathrm{~km}$ in $20 \mathrm{~min}$

\section{Progression}

A new 6MWT may be administered at the end of the $3^{\text {rd }}$ week of the ground walk training. The resultant 6MWD may be used to plot new walk training regimen as $80 \%, 90 \%$, and $100 \%$ of resultant new $6 \mathrm{MWD}$ for the next $1^{\text {st }}, 2^{\text {nd }}$, and $3^{\text {rd }}$ week, respectively, for $20 \mathrm{~min}$.

\section{Outcome Measures to be Used in Walk Training AsSESSMENT}

\section{Six-minute walk distance}

Maximal distance covered in $6 \mathrm{~min}$. Although literature claims its variability, the validity and reliability of 6MWD have proved to be useful. ${ }^{[17,18]}$ A clinical difference of $47-54 \mathrm{~m}$ is tested to be the best distance gain after intervention (responsiveness) in community dwellers and patients. ${ }^{[19]} 6 \mathrm{MWD}$ is also useful in monitoring disease progression. Further, $6 \mathrm{MWD}<350 \mathrm{~m}$ is associated with higher mortality rates in participants. ${ }^{[20]}$

\section{Predicted ideal walk distance and percent predicted distance}

At present, there is a growing proportion of interest in the determination of country-specific reference values for identifying age, height, weight, and gender predicted ideal walk distance..$^{[9,21]}$ On the comparison between actual and ideal 6MWD (percent predicted distance), the lag of the patient's ability behind their healthy peers can easily be made. This can be used for measurement and prognosis of the treatment purpose also. ${ }^{[21]}$

\section{Six-minute walk work}

The 6-min walk work (6MWW) is calculated by body weight. ${ }^{[22]}$ $6 \mathrm{MWW}=$ actual $6 \mathrm{MWD} \times$ body weight. Overweight, sleep apnea, and geriatric individuals can track their improvement in the body weight regulation by indirectly measuring $6 \mathrm{MWW}$. However, the normative values are yet to be studied.

\section{Six-minute walk pulse}

Probably, this may be a new determinant of autonomic impact on the functional walk capacity. 6MWP = actual $6 \mathrm{MWD} \times$ pulse rate during peak walk (rate/minute). $6 \mathrm{MWP}$ may indirectly determine the sympathetic withdrawal or parasympathetic supremacy after walk training. ${ }^{[23]}$ The normative values are yet to be studied.

\section{Desaturation index}

This may be a new index for monitoring desaturation in cardiopulmonary and vascular disorder individuals. Desaturation index may be indicated as

$$
\begin{aligned}
D I & =\frac{\text { Actual } 6 M W D}{(\Delta \text { walk saturation })} \\
& =\frac{\text { Actual } 6 M W D}{(\text { Peak walk saturation - resting saturation })}
\end{aligned}
$$

\section{Safety Concerns}

$6 \mathrm{MWT}$ is easy to use but not without minimal risks such as dyspnea, angina, leg fatigue, and claudication. ${ }^{\left[{ }^{9,24}\right]}$ According to the ATS criteria, the safety of 6MWT can be enhanced by appropriate environment accessible to resuscitation, oxygen supplementation, and first aid. Further, the presence of a physician is not mandatory since it is not a maximal exercise testing but requires the presence of exercise professional with current certification in basic life support and exercise testing. ${ }^{9]}$

\section{Conclusion}

An attempt has been made to quantify ground or treadmill walk intensity based on 6MWD. This may be simple to apply, quantify, improve, and appraise the effects of walking in community-dwelling individuals and patients. This may guide the physicians and novice therapists appropriately for 
the walking exercise prescription in community dwellers and COPD where sophisticated exercise programs are in shortage.

\section{Acknowledgment}

The author (BC) wishes to thank his colleagues Mr. Prabu Raja and Mr. Mathew Sunil Varre, Assistant Professors for their moral support and intellectual inputs in manuscript drafting. He extends his gratitude to his HOD, Dr. Fiddy Davis, for his research motivation.

\section{Financial support and sponsorship}

Nil.

\section{Conflicts of interest}

There are no conflicts of interest.

\section{ReFERENCES}

1. Sanseverino MA, Pecchiari M, Bona RL, Berton DC, de Queiroz FB, Gruet $\mathrm{M}$, et al. Limiting factors in walking performance of subjects with COPD. Respir Care 2018;63:301-10.

2. Spruit MA, Pitta F, McAuley E, ZuWallack RL, Nici L. Pulmonary rehabilitation and physical activity in patients with chronic obstructive pulmonary disease. Am J Respir Crit Care Med 2015;192:924-33.

3. Shin KC. Physical activity in chronic obstructive pulmonary disease: Clinical impact and risk factors. Korean J Intern Med 2018;33:75-7.

4. Burtin C, Langer D, van Remoortel H, Demeyer H, Gosselink R, Decramer $\mathrm{M}$, et al. Physical activity counselling during pulmonary rehabilitation in patients with COPD: A Randomised Controlled Trial. PLoS One 2015;10:e144989.

5. Fabre C, Chehere B, Bart F, Mucci P, Wallaert B, Grosbois JM, et al. Relationships between heart rate target determined in different exercise testing in COPD patients to prescribed with individualized exercise training. Int J Chron Obstruct Pulmon Dis 2017;12:1483-9.

6. Mador MJ, Modi K. Comparing various exercise tests for assessing the response to pulmonary rehabilitation in patients with COPD. J Cardiopulm Rehabil Prev 2016;36:132-9.

7. Celli B, Tetzlaff K, Criner G, Polkey MI, Sciurba F, Casaburi R, et al. The 6-minute-walk distance test as a chronic obstructive pulmonary disease stratification tool. Insights from the COPD biomarker qualification consortium. Am J Respir Crit Care Med 2016;194:1483-93.

8. Morales-Blanhir JE, Palafox Vidal CD, Rosas Romero Mde J, García Castro MM, Londoño Villegas A, Zamboni M, et al. Six-minute walk test: A valuable tool for assessing pulmonary impairment. J Bras Pneumol 2011;37:110-7.

9. ATS Committee on Proficiency Standards for Clinical Pulmonary Function Laboratories. ATS statement: Guidelines for the six-minute walk test. Am J Respir Crit Care Med 2002;166:111-7.

10. Chen H, Liang BM, Tang YJ, Xu ZB, Wang K, Yi Q, et al. Relationship between 6-minute walk test and pulmonary function test in stable chronic obstructive pulmonary disease with different severities. Chin Med J (Engl) 2012;125:3053-8.

11. Chetta A, Zanini A, Pisi G, Aiello M, Tzani P, Neri M, et al. Reference values for the 6-min walk test in healthy subjects 20-50 years old. Respir Med 2006;100:1573-8.

12. Marinho PE, Raposo MC, Dean E, Guerra RO, de Andrade AD. Does verbal encouragement actually improve performance in the 6-minute walk test? Physiother Theory Pract 2014;30:540-3.

13. Zainuldin R, Mackey MG, Alison JA. Prescription of walking exercise intensity from the 6-minute walk test in people with chronic obstructive pulmonary disease. J Cardiopulm Rehabil Prev 2015;35:65-9.

14. Pomidori L, Contoli M, Mandolesi G, Cogo A. A simple method for home exercise training in patients with chronic obstructive pulmonary disease: One-year study. J Cardiopulm Rehabil Prev 2012;32:53-7.

15. Kirkham AA, Pauhl KE, Elliott RM, Scott JA, Doria SC, Davidson HK, et al. Utility of equations to estimate peak oxygen uptake and work rate from a 6-minute walk test in patients with COPD in a clinical setting. J Cardiopulm Rehabil Prev 2015;35:431-8.

16. Leung RW, Alison JA, McKeough ZJ, Peters MJ. Ground walk training improves functional exercise capacity more than cycle training in people with chronic obstructive pulmonary disease (COPD): A randomised trial. J Physiother 2010;56:105-12.

17. Andrianopoulos V, Holland AE, Singh SJ, Franssen FM, Pennings HJ, Michels AJ, et al. Six-minute walk distance in patients with chronic obstructive pulmonary disease: Which reference equations should we use? Chron Respir Dis 2015;12:111-9.

18. Durheim MT, Smith PJ, Babyak MA, Mabe SK, Martinu T, Welty-Wolf KE, et al. Six-minute-walk distance and accelerometry predict outcomes in chronic obstructive pulmonary disease independent of Global Initiative for Chronic Obstructive Lung Disease 2011 Group. Ann Am Thorac Soc 2015;12:349-56.

19. Zanini A, Aiello M, Adamo D, Casale S, Cherubino F, Della Patrona S, et al. Estimation of minimal clinically important difference in EQ-5D visual analog scale score after pulmonary rehabilitation in subjects with COPD. Respir Care 2015;60:88-95.

20. Holland AE, Hill CJ, Rasekaba T, Lee A, Naughton MT, McDonald CF, et al. Updating the minimal important difference for six-minute walk distance in patients with chronic obstructive pulmonary disease. Arch Phys Med Rehabil 2010;91:221-5.

21. Güngör G, Karakurt Z, Adigüzel N, Aydin RE, Balci MK, Saltürk C, et al. The 6-minute walk test in chronic respiratory failure: Does observed or predicted walk distance better reflect patient functional status? Respir Care 2013;58:850-7.

22. Carter R, Holiday DB, Nwasuruba C, Stocks J, Grothues C, Tiep B, et al. 6-minute walk work for assessment of functional capacity in patients with COPD. Chest 2003;123:1408-15.

23. Richter MJ, Milger K, Tello K, Stille P, Seeger W, Mayer E, et al. Heart rate response during 6-minute walking testing predicts outcome in operable chronic thromboembolic pulmonary hypertension. BMC Pulm Med 2016;16:96.

24. Roberts MM, Cho JG, Sandoz JS, Wheatley JR. Oxygen desaturation and adverse events during 6-min walk testing in patients with COPD. Respirology 2015;20:419-25. 